\title{
HOLOGRAFİK SANATTA KULLANILAN HOLOGRAM ÇEŞİTLERİ
}

\author{
TYPES OF HOLOGRAMS USED IN HOLOGRAPHIC ARTS
}

Vildan IŞIK ${ }^{1}$

$\ddot{O} \mathbf{z}$

Holografi, 1960'ların sonlarından itibaren sanatsal bir ifade aracı olarak kullanılmaktadır. Bu çalışma; hologram çeşitleri, hologramların nasıl sınıflandırıldığı ve sanatta kullanılan hologram çeşitleri üzerinedir. Holografik sanatın kendine özgü geliştirdiği terimlerinin de yer aldığı bu araştırma göstermiştir ki holografi; izleyicinin zaman, mekân, boyut, ses, renk, hareket, sanallık ve gerçeklik algısına eşzamanlı olarak ulaşabilme özelliğine sahip önemli bir sanatsal araçtır. Bu özellikleri sayesinde holografinin sanatta kullanımı gelecekte de önemini korumaya devam edecektir.

Anahtar Kelimeler: Hologram çeşitleri, holografi, hologram, hologramların sınıflandırılması, holografik sanat

\begin{abstract}
Holography is a technique that includes many hologram types. Some of these types could be used in the holographic arts; however each hologram type is not appropriate for artistic use. In order to understand which of them could be used in arts, firstly the classification of this technique as well as the types should be known. In this study, holograms are classified, and hologram types used in the holographic art are examined with examples.
\end{abstract}

Key Words: Classification of holograms, types of hologram, holography, hologram, holographic art

\footnotetext{
${ }^{1}$ Melikşah Üniversitesi, Mühendislik Mimarlık Fakültesi, Endüstri Ürünleri Tasarım Bölümü, Talas-Kayseri/Türkiye. e-posta: vldnsk@gmail.com
} 


\section{Giriş}

Işığın ve sesin kaydı ve yeniden yapımına dayanan bir teknik olan holografi, 1940'ların sonlarından ortaya çıkmış, 1960'lı yılların sonlarından itibaren sanatta da kullanılmaya başlamış ve 1980'lerin sonlarına doğru ayrı bir sanat dalı olarak kabul görmüştür (Saxby, 1994 ; Johnston, 2005). Anlaşılması, öğrenilmesi ve uygulanması kolay olmayan bu teknik ile birbirinden farklı yöntemlerle hologram elde edilmesi mümkündür. Yöntemlerin çok olması çeşitlerin sayısını arttırmış ve tekniğin anlaşılmasını karmaşıklaştırmıştır. Bu sebeple holografiye ait sınıflandırma ve çeşitlerin bilinmesi, holografik sanatı anlama ve değerlendirmede olduğu kadar sanatsal üretimde hangi hologram çeşidinin tercih edilebileceği hususunda da önemli ölçüde fayda sağlayacaktır.

Bu çalışmanın ilk iki bölümünde hologram çeşitleri ve sınıflandırılması hakkında bilgi verilmiş üçüncü ve dördüncü bölümlerde ise holografik sanatta sıklıkla kullanılan hologram çeşitleri - yansıma, Denisyuk, geçirgen, gökkuşă̆ı, geçirgen beyaz ışık, atımlı lazer, çok kanall, $360^{\circ}$ hologram ile holografik stereogram ve interferogram - ile bu sanata özgü üretilen - gölgekayıt, holografik portre, bileşik hologram, holomontaj, resimsel holografi, holoresim, holokinetizm, holomobil, holoheykel, çevresel holografi ve holografik yerleştirme terimleri incelenerek örnekleri ile anlatılmıştır.

\section{HOLOGRAM ÇEŞITTLERI}

Hologramlar temel olarak geçirgen, yansıma, ana ve kopya hologram başlıkları altında toplanabilir. Ancak hologram çeşitlerinin anlaşılmasında bu temel başlıklar yeterli olmamaktadır. $\mathrm{Bu}$ sebeple geçmişten günümüze üretilmekte olan ve halen geliştirilmesine devam edilen hologram çeşitleri, Türkçe karşılıkları ile birlikte bir Tablo 1'de verilmiştir (Işık, 2012: 63-65). Burada çeşitlere ilişkin belirtilmesi gereken önemli bir husus vardır: Bir hologram çeşidi aynı anda başka bir hologram çeşidine ya da sınıfına da dâhil olabilmektedir. Örneğin Denisyuk hologramı aynı zamanda; yansıma, tek 1şınlı, eksende ve ana hologram çeşididir ve hem H1 hem de 2D/3D sınıflamasına ait bir hologramdır. Hologramın hologramı olan geçirgen hologram-H2'ler ise aynı zamanda iki aşamalı, eksen dişı ve geçirgen hologram çeşididir ve beyaz 1 şı geçirgen hologram ya da Benton hologramı olarak da ifade edilmektedir. Ayrıca geçirgen-H2 hem kopya hem de 2D/3D hologramdır. Gökkuşağ1 hologram ise hem bir geçirgen beyaz 1şık hologram çeşidi hem de çok renkli hologram çeşididir. Kısacası tanımlanan her hologram çeşidi aynı zamanda başka bir hologram çeşidini ve sınıfını içerebilmektedir. 
Tablo 1: Hologram çeşitleri

\begin{tabular}{|c|c|}
\hline Akustik Hologram & Acoustical Hologram \\
\hline Ana Hologram & Master Hologram \\
\hline Analog Hologram & Analog Hologram \\
\hline Atımlı Lazer Hologramı & Pulse Laser Hologram \\
\hline Bilgisayarla Oluşturulmuş Hologram & Computer-Generated Hologram-CGH \\
\hline Bilgisayarla Oluş̧turulmuş Holografik Stereogram & Computer-Generated Holographic Stereogram-CGHS \\
\hline Bilgisayarla Oluşturulmuş Fresnel Hologram & Computer-Generated Fresnel Hologram CGFH \\
\hline Çok Kanallı Hologram & Multi-Channel Hologram \\
\hline Çok Pozlu Hologram & Multiple Exposure Hologram \\
\hline Çok Renkli Hologram & Multi-Color Hologram \\
\hline Denisyuk Hologramı & Denisyuk Hologram \\
\hline Elektro-Hologram (Holovideo) & Electro-Hologram (Holovideo) \\
\hline Eksen D1ş1 Hologram & Off-Axis Hologram \\
\hline Elektron Mikroskobu Hologram1 & Electron Microscope Hologram \\
\hline Faz Hologramı & Phase Hologram \\
\hline Fourier Hologramı (Fraunhofer Hologramı) & Fourier Hologram (Fraunhofer Hologram) \\
\hline Fresnel Hologramı & Fresnel Hologram \\
\hline Gabor Hologramı & Gabor Hologram \\
\hline Geçirgen Beyaz Işık Hologramı & White-Light Transmission Hologram-WLT \\
\hline Geçirgen Hologram & Transmission Hologram \\
\hline Gerçek Renkli Hologram & True Color Hologram \\
\hline Gökkuşağ1 Hologram & Rainbow Hologram \\
\hline Gölgekayıt & Shadowgram \\
\hline Görüntü Düzlemi Hologramı & Image Plane Hologram \\
\hline Günış1ğ1 Hologram & Solar Hologram \\
\hline Hacim Taramalı Hologram & Volumetric Hologram \\
\hline Hacim Taramalı Kuantum Hologramı & Volumetric Quantum Hologram \\
\hline Holografik İnterferogram & Holographic Interferogram \\
\hline Holografik Sinema & Holographic Movie \\
\hline Holografik Stereogram & Holographic Stereogram \\
\hline Holografik TV & Holographic TV \\
\hline İçbükey Hologram & Alcove Hologram \\
\hline Kopya Hologram & Copy Hologram \\
\hline Kabartma Hologram & Embossed Hologram \\
\hline Kuantum Hologram & Quantum Hologram \\
\hline Lazerle Görülebilen Hologram & Laser-Viewable Hologram \\
\hline Leith-Upatnieks Hologramı & Leith-Upatnieks Hologram \\
\hline Lippmann Hologram & Lippmann Hologram \\
\hline Moleküler Hologram & Moleculer Hologram \\
\hline Nokta Matris Hologram & Dot Matrix Hologram \\
\hline Odaklanmış Görüntü Hologramı & Focused Image Hologram \\
\hline Renksiz Hologram & Achromatic Hologram \\
\hline Sandviç Hologram & Sandwich Hologram \\
\hline Say1sal Hologram & Digital Hologram \\
\hline Sayısal Görüntü Düzlemi Hologramı & Image-Plane Digital Hologram \\
\hline Silindirik Hologram & Cylindrical Hologram \\
\hline Tek Renkli Hologram & Monochromatic Hologram \\
\hline Tek Işınlı Hologram & Single Beam Hologram \\
\hline Tek Aşamalı Hologram & Single-Step Hologram \\
\hline Tümleştirilmiş Hologram & Integral Hologram \\
\hline Yalanc1 Renkli Hologram & Pseudo Color Hologram \\
\hline Yansıma Hologram & Reflection Hologram \\
\hline X-Işını Floresans Hologramı & X-Ray Fluorescence Hologram -XFH \\
\hline $360^{\circ}$ Hologram & $360^{\circ}$ Hologram \\
\hline
\end{tabular}




\section{HOLOGRAMLARIN SINIFLANDIRILMASI}

Çeşidine bağlı olarak hologramlar farklı özelliklere sahiptir ve sınıflandırmada bu oldukça önemlidir. Genel olarak en önemli özelliklerden biri farklı açılardan görülebilme yani paralaks özelliğidir. Kayıt türüne göre hologramlarda yatay ve düşey paralaks ayrı ayrı olabildiği gibi her ikisi birden de bulunabilmektedir. Örneğin yansıma hologram, düşey ve yatay paralaks etkisinin her ikisine de sahip olabilirken, geçirgen beyaz ş̧ık hologram sadece yatay paralaks ya da sadece dikey etkiye sahiptir. Her iki hologram da 2D/3D sinıfına dâhildir. Yatay ve düşey paralaksın aynı anda bulunduğu hacim taramalı hologram ise 3D sınıfına ait bir hologram çeşididir. Hologramların diğer önemli bir özelliği ise holografik film düzleminin önünde (gerçek/ortroskobik) ve holografik film düzleminin arkasındaki (sanal/sudoskobik) alan görüntüsüne sahip olmasıdır. Yani hologram, film düzleminin ön yüzünden içeri doğru bir alan derinliği ile film düzleminin tersine çevrilmesi ile düzlemden dışarı doğru taşan sanal bir görüntü verebilmektedir.

Çeşitlerine ve bu çeşitlere bağlı özelliklere göre hologramların; kullanım ve inceleme alanları, kayıt elemanlarl, holografik nesnenin niteliği, banyo aşaması, kaynak ve nesne ışınları, kopyalama ve çoğaltma yöntemleri, yapım aşamaları, boyutları, renkleri ve görüntülenmesi başlıkları altında sınıflandırılması mümkündür (Işık, 2012: 52-62).

Kullanım ve İnceleme Alanlarına Göre Hologramlar. Hologramlar optik, elektronik, tıp, bilişim, mimari, müzecilik, sanat, kültür endüstrisi, askeri ve güvenlik gibi pek çok alanda farklı amaçlarla kullanılmaktadır. Her alanın kendine uygun kullandığı farklı çeşitler olabilmektedir. Örneğin müzecilikte, arşivlemede Denisyuk hologramı, eski eserlerdeki tahribatın incelenmesinde ise holografik interferogram kullanılmıştır. Tıbbi hologramlar, sanatsal hologramlar ve güvenlik hologramlarl gibi sinıflandırmalar olsa da her kullanım ve inceleme alanına göre genel bir sinıflandırma yoktur.

Kayıt ve Yeniden Yapım Elemanlarına Göre Hologramlar. Hologram kaydında ve yeniden yapımında kullanılan mercekler, aynalar, filtreler, prizmalar vb. gibi holografik optik elemanlar (HOE) ve elektronlar, kristal ekranlar, kameralar, bilgisayarlar vb. gibi holografik elektronik elemanlar (HEE)'a göre farklı hologram çeşitleri ortaya çıkmaktadır.

Holografik Nesnenin Niteliğine Göre Hologramlar. Holografide neyin hologramı alınıyorsa bu, holografik nesne olarak tanımlanmaktadır. Holografik nesne; canlı veya cansız, hareketli veya hareketsiz bir nesneyi ifade edebildiği gibi ses frekanslarını, mikroskobik canlıları, gözle görülemeyecek derecede küçük elektronları ve atom altı parçacıklarını da 
ifade edebilmektedir. Bununla birlikte sadece lazer ışınları ile plaka üzerinde dalga deseninin oluşturulması da mümkündür. Ayrıca bazen bir hologram, başka bir hologramın nesnesi de olabilmektedir ki bunlar bir hologramın hologramıdır. Hologram kaydındaki holografik nesnenin niteliğine bağlı olarak elektron mikroskobu hologramı, atımlı lazer hologramı, kuantum hologram, akustik hologram vb. gibi farklı hologram çeşitleri ortaya çıkmaktadır.

Banyo Aşamasına Göre Hologramlar. Bazı hologramlar, kayıt yapıldıktan sonra tıpkı analog fotoğraf kaydındakine benzer şekilde karanlık odada yapılan banyo sürecinden geçmektedir. Kaydedilen görüntünün sabitlendiği banyo sürecinde hologramın parlaklık ve şeffaflığını arttırmak için çeşitli kimyasallarla ayrıca bir de ăgartma işlemi (görsel 1) uygulanmaktadır. Ağartılmış bu hologram çeşidi ise faz hologramı olarak adlandırılmaktadır. Sanatçılar bazen izleyiciye hologramın 'arkasını' göstermek için banyodan sonra ağartma yaparak şeffaflaştırmakta ve iki tarafından da görülecek şekilde asmaktadır. (Hologram banyosu ve ağartma işlemi hakkında

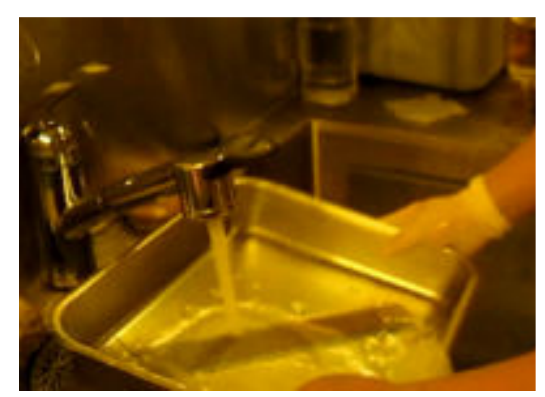

Görsel 1. Ağartma

Banyo işleminin ardından kimyasallarla ağartma yapılmakta, su ile durulanmakta ve holografik film şeffaflaştırılmaktadır. Hangyo Int. Corp. R\&D Center Holography Lab., Seul-G.Kore, fotoğraf: Vildan Işı1k. detaylı bilgi için bkz: Işık, 2012: 122-125)

Kaynak ve Nesne Işınlarına Göre Hologramlar. Holografik kayıtta kullanılan kaynak ve nesne ışın'larının konumları, sayıları ve açı farklılıkları çok önemlidir. Bunlar aynalar, mercekler ve ışın ayırıcılar gibi kayıt elemanları ile değiştirilebilmektedir. Kaynak ve nesne 1şınlarının, kayıt plakasının önünde ya da arkasında, eksende ya da eksen dışında konumlandırılmasına bağlı olarak farklı çeşitlerin ortaya çıkması sağlanmıştır. Bunlar; Denisyuk, yansıma, geçirgen, tek ışınlı, eksende, eksen dışı, tek ışınlı, çift ışınlı vb. gibi farklı birer hologram çeşidi olarak tanımlanabilmektedir.

Yapım Aşamalarına Göre Hologramlar. Yapım aşamalarına göre hologramları tanımlamak için $\mathrm{H} 1$ ve $\mathrm{H} 2$ sembolleri kullanılmaktadır. Bazı çeşitlerde örneğin sandviç hologramda H3, H4 sembolleri de kullanılmaktadır (Tornari, 2007: 767-768). H1; ana hologram olarak kullanılan tek aşamalı hologram'1, $\mathbf{H 2}$ ise hologramın hologramı olan bir kopya hologram'1 ya da iki aşamalı hologram'1 tanımlamak için kullanılmaktadır.

Kopyalama ve Çoğaltma Yöntemlerine Göre Hologramlar. Hologramların çeşitli yöntemlerle kopyalanması ve çoğaltılması mümkündür. Holografinin sanatsal potansiyelini de önemli ölçüde değiştiren bu yöntemleri genel olarak şu başlıklar altında toplayabiliriz: 


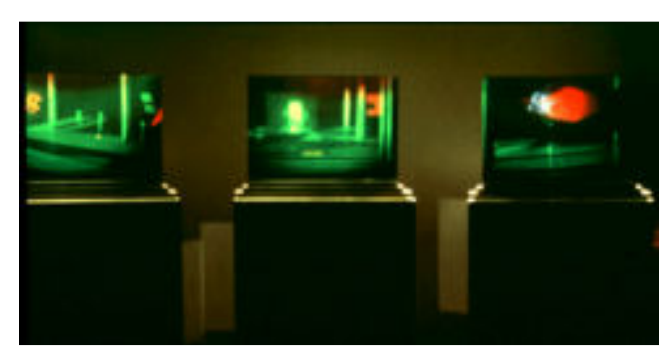

Görsel 2. Hologramın hologramı Dan Schweitzer, The Gallery Triptych (Galeri Üçlemesi), Üç farklı hologramın hologramına ait bu çalışmada izleyici aynı anda 18 hologramı görebilmektedir (Schweitzer, 2000, alchemists.com).

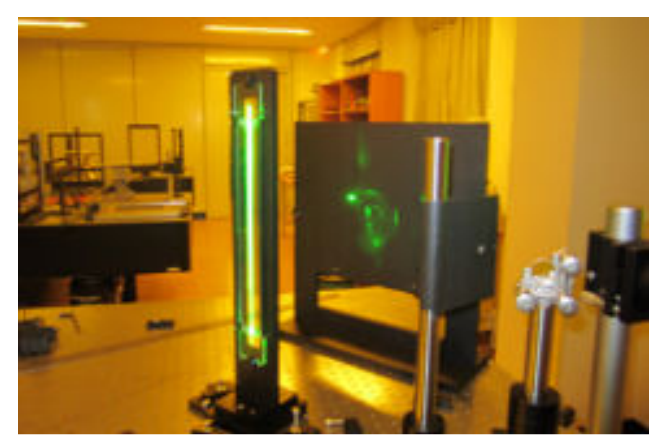

Görsel 3. H1 hologramdan H2 kaydı.

Öndeki dikey ana hologramdan arkadaki dikdörtgen holografik plakaya ikincil bir hologram kaydı yapılabilmektedir. Hangyo Int. Corp. R\&D Center Holography Lab., SeulG.Kore, fotoğraf: Vildan Işık.

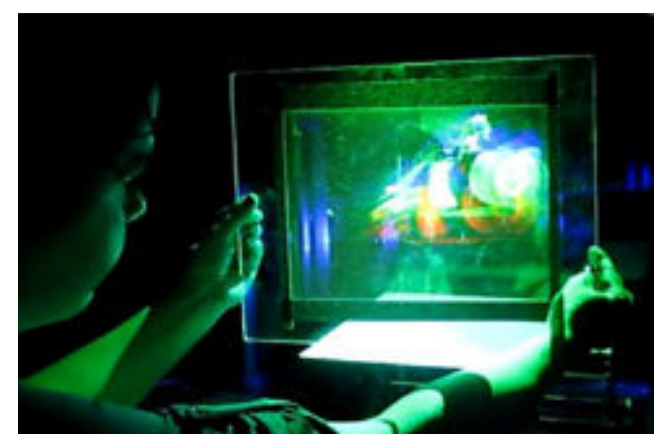

Görsel 4. 2D/3D hologram

Hologram kaydından gerçek (ortroskobik) ve sanal (sudoskobik) alanın incelenmesi, fotoğraf: Kwang Ho Ok (Işık, 2012).

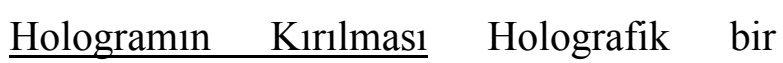
plaka/film kırılsa ya da kesilse bile her bir parçasında bütüne ait bilgiyi muhafaza etmektedir. Hologramın en önemli özelliklerinden biri olan bu özellik her hologram çeşidinde bulunmamaktadır. Geçirgen-H1 gibi ana hologram'lar bu türden hologramlardır. Holografik plakanın hem kendisi hem de de kırık bir parçası bütünün bilgisine sahip olduğu için ayrı ayrı her biri bir ana hologram olarak kullanılabilir.

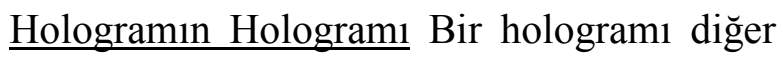
bir hologramın nesnesi yapmak ve bu yolla yeni bir hologram üretmek mümkündür (görsel 2, 3). Kopya hologram ya da H2, H3 vb. olarak tanımlanan geçirgen beyaz ışık, çok pozlu, sandviç gibi hologramlar bu türdendir.

Sayısal Çoğaltma Hologramların kamera ve bilgisayarlarla sayısal yollarla da çoğaltılabilmesi mümkündür. Sayısal ve bilgisayarla oluşturulmuş hologram çeşitleri ile çoğaltma sağlanabilir.

Boyutlarına Göre Hologramlar. 'Boyut' x, y, $\mathrm{z}$ düzlemlerini ya da hologramın ölçülerini ifade etmektedir. Hologramları; hacim ya da düzleme göre kalın, ince, ebatlarına göre küçük ya da büyük ve boyut sayılarına göre $1 \mathrm{D}, 2 \mathrm{D}, 2 \mathrm{D} / 3 \mathrm{D}$ ve $3 \mathrm{D}$ olarak üç farklı şekilde sınıflandırmak mümkündür.

$\underline{1 D}$ hologram tek eksenli ( $\mathrm{x}, \mathrm{y}$ ya da $\mathrm{z}$ ekseni) verilerle elde edilen tek boyutlu hologram, çizgisel resim ifade kapasitesine sahiptir. Örneğin akustik hologramda tek boyutlu ses frekanslarının holografik kaydı görüntü ile senkronize edilmektedir.

2D hologram ifadesi; holografik kaylt malzemesine, paralaks etkisi olmayan ancak çeşitli renklerin görülebildiği holografik baskl'lara ve yansıtma yoluyla görüntülenen, paralaks olmayan iki boyutlu holografik yansıtım'a. işaret etmektedir. 


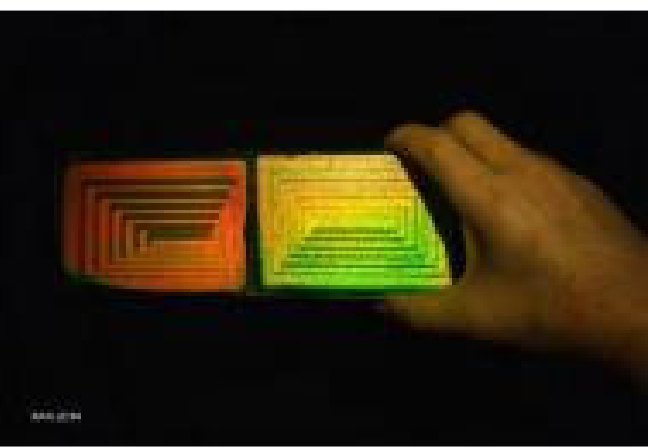

Görsel 5. Hologramda ortroskobik ve sudoskobik alan

Dikromat yansima hologram, 1983, Holocrafts (Razutis, www.facebook.com).

$\underline{\text { 2D/3D hologram }}$ Burada 3D ifadesi hologramın paralaks özelliğini, gerçek (ortroskobik)-sanal (sudoskobik) alanı (görsel 4, 5) ya da tek yüzeydeki üst üste kaydedilmiş görüntüler arasındaki mesafeyi ifade etmektedir. Duvara asılabilen ve sanatçılar tarafından da sıklıkla kullanılan pek çok çeşit için ya da güvenlik sistemlerinde kullanılan bazı holografik baskılar için 2D/3D ifadesi kullanılmaktadır.

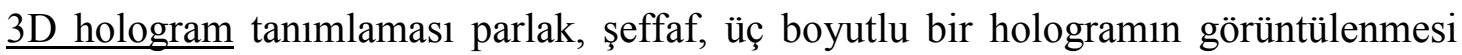
anlamında kullanılmaktadır. Çevrelerinde dönülebilen her bakış açısından görülebilen hacim taramalı ve $360^{\circ}$ silindirik hologram'lar bu türdendir.

Renklerine Göre Hologramlar. Kırmızı, mavi, yeşil lazer 1şınlarının ayrı ayrı ya da bir arada kullanılmasına göre farklı hologram çeşitleri ortaya çıkmaktadır. Bunlar; renksiz, tek renkli, tam renkli, gerçek renkli, yalancı renkli ve çok renkli gibi isimler alır.

Görüntülenmesine Göre Hologramlar. Kayıt türüne bağlı olarak hologramlar farklı şekillerde görüntülenmektedir. Bazı hologramlar sadece lazerle görülebilirken bazıları için özel bir 1şık kaynağına ihtiyaç duyulmakta bazıları ise sıradan bir 1şık kaynağı ile ya da günışığında görülebilmektedir. Örneğin geçirgen-H1 hologramlar yalnızca lazer ile görülebilirken gökkuşağ , günışı̆̆g ve kabartma hologram gibi hologramlar güneş 1şı̆̆1 ya da bir sıradan 1şığa, hacim taramalı hologram'in görülebilmesi için ise özel bir görüntüleme alanı ve cihazına ihtiyaç duyulmaktadır.

\section{SANATSAL AMAÇLA KULLANILAN HOLOGRAM ÇEŞITLERİ}

Bazı hologram çeşitleri sanatsal ifade aracı olarak kullanıma son derece uygunken bazıları üretme, görüntüleme veya maliyet bakımından pek uygun değildir. Örneğin havada tam bir 3D görüntü oluşturan hacim taramalı hologram ve bilimsel araştırmalarda kullanılan kuantum gibi çeşitler sanatta kullanılmamaktadır. Bu bölümde 1960'lı yıllardan günümüze sanatçıların tarafından kullanılan hologram çeşitlerinden bazılarına yer verilmiştir. Bunlar; sanatsal amaçla sıklıkla kullanılan yansıma hologram, Denisyuk hologramı, geçirgen hologram, gökkuşağı hologram, geçirgen beyaz ışık hologramı, atımlı lazer hologramı, çok kanallı hologram, $360^{\circ}$ hologram, holografik stereogram ve holografik interferogram' dır. 
Yansıma Hologram. Bu hologramlar tek renkli veya çok renkli olabildiği gibi H1 ya da H2 de olabilmektedir. Kayıt sırasında kaynak ve nesne ışını kayıt malzemesinin aksi yönündedir. Yeniden yapımında ise ön cepheden ve direkt olarak yaklaşık $45^{\circ}$ lik açı ile beyaz 1şıkla aydınlatılmak zorundadır. Yansıma hologramların alan derinliği, geçirgen hologramlardan daha küçüktür ve gerçek görüntü ile sanal görüntü yaklaşık olarak $25-30 \mathrm{~cm}$. ile sınırlanmıştır. Buna rağmen dikey ve yatay olarak paralaks bakış açısını muhafaza etmektedir. (Leonardo, 2001: 378). Yansıma hologramlarla çalışıldığı zaman ağartma çok önemlidir çünkü bu hologramlar çok küçük miktarda doğal parlaklığa sahiptir. Ağartma yoluyla daha parlak ve şeffaf hologramlar elde edilebilmektedir.

Denisyuk Hologramı. 1961'de Rusya'da Juri N. Denisyuk tarafindan bulunması sebebiyle bu isimle bilinmektedir. Denisyuk hologramı hem nesne hem de kaynak ışınları için tek bir lazer 1şınının kullanıldığı bir yansıma hologramdır. Bu hologramlar, beyaz 1şıkta görülebilen ilk H1 hologramlardır. Genellikle oldukça küçük alan derinliğe sahip olmasına rağmen üç boyutlu nesnenin son derece gerçekçi görüntüsünü verebilmektedir. Görüntünün uygun parlaklığı ve berraklığı için bütün yansıma hologramlarda olduğu gibi Denisyuk hologramlarında da kaydedilen görüntünün banyo işlemi ile sabitlemenin ardından ağartılması gerekmektedir (Leonardo, 2001: 371, 376). Denisyuk hologramları önceleri dokümantasyon için müzelerdeki değerli parçaların kaydedilmesi ve görüntülenmesi amacıyla daha sonra geliştirilerek farklı amaçlarla kullanılmaya başlamıştır (obel.ee.uwa.edu, 2011). Sanatçılar tarafından da sıklıkla kullanılan bu hologram çeşidine Al Razutis'in 36 Denisyuk hologramını birleştirerek oluşturduğu Newtoncu Galaksi Montaj Hattı isimli çalışması örnektir. Her bir parçada dişli görüntüleri olan bu çalışmada gerçek (ortroskobik) ve sanal (sudoskobik) holografik alan görüntüsü birlikte kullanılmıştır (Razutis ile yapılan yazışmalarda verilen bilgi).

Geçirgen Hologram. Bu hologramda hem kaynak hem de nesne 1şınları holografik plaka ile aynı tarafta kullanılmaktadır. Bir geçirgen hologramın alan derinliği, yansıma hologramlardan daha büyüktür. Çoğu geçirgen hologram-H1'ler sadece lazerle görülebilen türdendir. Geçirgen hologramlar istendiğinde ana hologram olarak kullanılabilir ve başka bir holograma aktarılabilir. Böylelikle geçirgen hologram-H2'ler oluşturulabilir. Benton tarafından geliştirilmiş bu yöntem sayesinde lazere ihtiyaç olmadan diğer 1şık kaynakları ile görülebilen hologramlar ortaya çıkmış ve sanatçılar tarafından daha sık tercih edilir olmuştur (Leonardo, 2001: 379). Paula Dawson'1n Avustralyalı müzik grubu Absent Friends için 
yaptığ1 çalışması, lazer geçirgen hologram çeşidine örnektir. (Geçirgen hologram-H1 ve geçirgen hologram-H2 kaydının detaylı anlatımı bkz. Işık, 2012: 113-132)

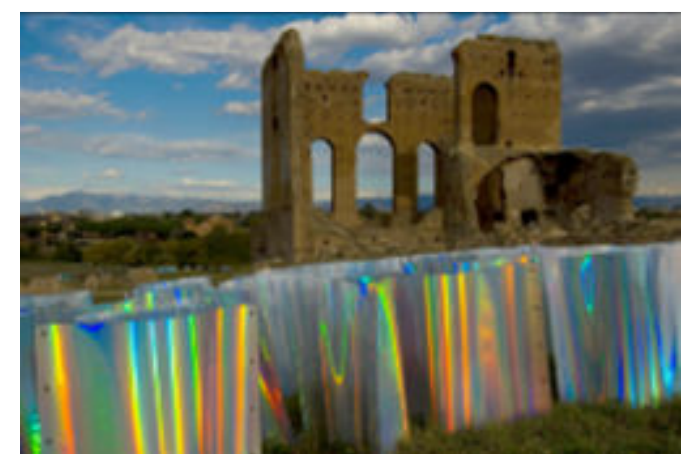

Görsel 6. Gökkuşağı Hologram

Setsuko Ishii, The Light and the History (Iș1k ve Tarih), 2007, Roma, İtalya, güneşe göre renk değiştiren gökkuşağı hologramlar (Sagnotti, 2007).
Gökkuşağı Hologram. Bir geçirgen beyaz 1şık hologramı olan gökkuşağı hologramlar, ana hologramdan üretilen ikincil veya bir kopya hologram çeşididir. Prizmanın içinden geçerken kırılan beyaz 1şık, görüntü yüzeyinde yatay düzlemde kırmızıdan mora renkli şeritlere ayrılarak emülsiyona nüfus etmekte ve renk değişimleri ortaya çıkmaktadır. Gökkuşağının bütün renklerinin sergilendiği bu hologramlar çok pozlu ve çok renkli olarak üretilebilmektedir. Gökkuşağı hologramlar, aydınlık ve parlak olmasına rağmen alan derinliği sınırlıdır (Leonardo, 2001: 378). Bu hologram çeşidinin günışığında görülebilir ve duvara asılabilir olması holografinin sanatsal potansiyelinin artmasını sağlamıştır (Johnston, 2005: 381). Setsuko Ishii'nin gökkuşağı hologramları ile yaptığı The Light and the History (Iş1k ve Tarih) isimli yerleştirmesi (görsel 6) bu hologram çeşidinin sanatsal kullanımına örnektir (Sagnotti, 2007).

Geçirgen Beyaz. Işık Hologramı. 1969'da ABD'de Stephen Benton tarafından geliştirildiği için Benton hologramı olarak da bilinen bu hologram çeşidi, ana hologramdan üretilmiş bir kopya hologramdır. $\mathrm{Bu}$ hologramlar, renksiz geçirgen hologram tekniği ile gökkuşağı hologramın renk kontrol tekniklerini ihtiva etmektedir. Sıklıkla, eksen dış1 holografik kayıt üretimi olan bu hologram, Denisyuk hologramından daha farklı tekniklerle elde edilmekte ve normal 1şıkta daha kolay görülebilmektedir. MIT ve Polaroid laboratuvarlarında holografinin gelişimi için çalışmalarda bulunan Benton'un teknoloji, bilim ve estetik araştırmalarını kapsayan ve Benton Holografisi olarak adlandırılan çalışmaları gerek bilimsel gerek sanatsal gerekse ticari alanda önemli gelişmeleri de beraberinde getirmiştir (mit.edu, 2003). Ön taraftan aydınlatılabilme özelliği ise kabartma hologram çeşidinin yapımını mümkün kılmaktadır. Üç boyutlu nesnenin sadece yatay paralaksının alınmasına ve renklerin yayılma alanı ile ideal mesafe önde sınırlanmış olmasına rağmen iki $\mathrm{m} 2$ nin üzerinde çok geniş olabilmektedir. Bazı holografi laboratuvarları $3 \mathrm{~m}^{2}$ lik oldukça büyük geçirgen beyaz 1şık hologramlarını üretebilmektedir. Özellikle geçirgen beyaz 1şık hologramları günışı̆̆ında görülebilir ve duvara asılabilir olması sebebiyle holografinin sanatsal potansiyelinin artmasında önemli bir rol oynamıştır (Leonardo, 2001: 379,380). 
Böylelikle sanatçılar, sadece lazerle görülebilen hologramları yapmak yerine günışı̆̆ında ya da halojen, led ya da sıradan ampullerle görülebilen hologramları sanatsal bir araç olarak kullanabilmeye başlamıştır. Sam Moree'nin 1997'deki Phoenix 46 (Anka Kuşu 46) isimli çalışması geçirgen beyaz ışık hologramının kullanımına örnektir (art-in-holography.org).

Atımlı Lazer Hologramı. Atımlı lazer, kısa ve sürekli olmayan şekilde, uyumlu ışık yayan güçlü bir katı hal lazeridir. Bu lazer, hareketli sahneleri ve canlı nesneleri kaydetmek için kullanılmaktadır. Sürekli dalga lazerini canlı ya da hareket eden nesnelerin hologramını elde etmek için kullanmak mümkün değildir (Leonardo, 2001: 378). Daha önceleri yalnızca cansız ve hareketsiz nesneler kaydedilebilirken atımlı lazer ile insan, hayvan, çiçek gibi canlı ya da dökülen su, kırılan yumurta, üfleme sabun köpükleri, saçılmış tüyler ve patlamış mısır gibi hareketli cansız nesnelerin de kaydedilebilmesi mümkün olmuştur. Bu lazer çeşidinin sanatçılar tarafından da kullanılabilir hale getirilmesi holografinin sanatsal potansiyelini de arttırmıştır. 1980'lerin başında İngiliz bilimci John Webster'in ticari olarak satılan bir atımlı yakut lazeri geliştirmesi, holografi sanatçılarına kolaylıklar sağlamıştır. Bu lazer, pahalı olmasına rağmen yine de kullanımı daha güvenilir ve daha kolaydır (holograms.co.uk: 2012). Peter Nicholson 1980-90'larda taşınabilir bir minyatür atımlı lazer ile portreci adını verdiği kamerayı geliştirmiş ve eşi Ana Maria Nicholson ile birlikte çok sayıda atımlı lazer hologramlar üretmiştir (Nicholson, 2009: 1-10).

Çok Kanallı Hologram. Bir hologram kalıbının çoklu pozlanması, maskeleme ya da üst üste yerleştirilmiş bir ana hologramın fotoğrafının çekilmesi ile oluşturulmaktadır. Bu amaçla birden fazla holografik plaka katmanlar halinde bir arada kullanılabilmekte, bir ya da birden fazla kalıpla çoklu pozlama yapılabilmektedir. Bu teknik sanatçılara renk ve biçimde manipülasyon yapma konusunda büyük bir esneklik sağlamaktadır. Sanatçılar tarafından sıkça kullanılan bu çeşitte pozlamalar; holografik nesne'nin değiştirilmesi, nesne ve kaynak ışınının aydınlatma oranları ya da açılarının değiştirilmesi, bölgesel maskeleme veya emülsiyon üzerindeki pozlama alanının değiştirilmesi gibi parametrelerle değiştirilebilmektedir (Leonardo, 2001: 374-376). Margaret Benyon'un 1985'te yaptığı Tiger Girl (Kaplan Kız) isimli hologramında hem kendi portresini hem de bir kaplan başını aynı hologram yüzeyine kaydetmiştir (web.mit.edu). 
$360^{\circ}$ Hologram. $360^{\circ}$ paralaks etkisi olan hologram yapmanın pek çok yolu vardır. $360^{\circ}$ holografik stereogram, $360^{\circ}$ silindirik hologram ve hacim taramall hologram bu hologram çeşitlerinden bazılarıdır (Saxby, 1994: 106). Hacim taramalı hologram'lar havada ‘yüzen', insanların etrafında dolaşarak tüm açılardan görebileceği görüntülerdir ancak kontrollü laboratuvar deneyleri dişında üretmek pek mümkün değildir. Günümüzde hacimsel görüntü üreten tek cihazı floresans buhar görüntüleme cihazıdır. Bu cihaz, havadaki görüntüleri görüntülemek için $1 s ̧ 1 k$ 1şınları ile birleştirilmiş civa buharı kullanmaktadır. Bu tekniğin olumsuz yanı, civa buharının 1şımasının yalnızca karanlıkta

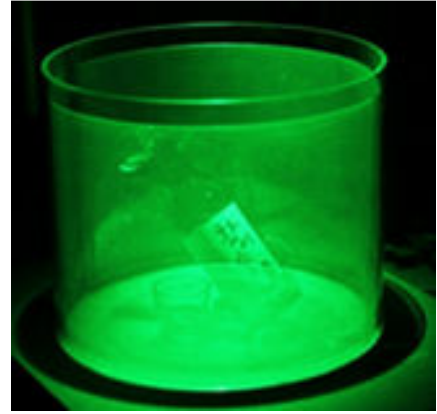

Görsel 7. Silindirik Hologram Vildan Işık, HoloSuret-IV, 2012, Soju şişesi ve bardakları, gümüş halide holografik film (Geola), $360^{\circ}$ silindirik hologram, R: 30 $\mathrm{cm}, \mathrm{h}: 23 \mathrm{~cm}$. Üretim yeri: Hangyo Int. Corp. R\&D Center Holography Lab., Seul-G.Kore. görülebilir olmasıdır (komar.cs.stthomas.edu). Sanatçılar tarafından sıklıkla kullanılanlar ise $360^{\circ}$ holografik stereogramlar ve $360^{\circ}$ silindirik hologramlardır. Bunlar çoğu zaman, bir eksen üzerinde sabit hızla dönen motorlu bir kaide üzerine konularak kullanılmaktadır. Vildan Işık'1n HoloSuret:IV (görsel 7) isimli çalışması 360 hologram çeşidine örnektir. Çalışma ayrı ayrı kaydedilen $180^{\circ}$ lik iki hologramın birleştirilmesi ile oluşturulmuştur. Sadece lazerle görüntülenebilen bu hologramda görüntü, silindirin ortasında havada oluşmaktadır.

Holografik Interferogram. Hareket eden ya da hareket ettirilen bir nesnenin çok küçük hareketlerini ve düşük aralıklardaki biçim bozulmalarını ölçmek için nesneden yansıyan lazer ışınlarıyla girişim saçaklarının, kayıt boyunca çoklu kaydının alındığı bir hologram çeşididir. Bu teknikte; tek nesne, tek yüzey ve tek malzeme kullanılarak iki ardıl görüntü aynı malzemeye kaydedilmektedir. $\mathrm{Bu}$ ardıl görüntüler, birbirini takip eden çok önemsiz hareketler ya da hareketin değiştirilmesi şeklinde olabilmektedir. $\mathrm{Bu}$ hareketler yüzeyde zebra çizgileri ve hareli bir etki oluşturmaktadır. Holografik interferometri oluşan bu siyah çizgi desenlerini, hareketi ölçmek amacıyla kullanmaktadır (MIT Leonardo, 2001: 375). Çizgilerde siyahın yokluğu hareketin yokluğu demektir. Holografik interferogram özellikle yüksek hassasiyeti olan yüzeylerdeki biçim bozulmalarının incelenmesi için optik veri sağlamaktadır (Cernecky, 2011). Eski tuval resimleri yüzeyleri ya da freskler gibi sanat eserlerindeki hasar ya da biçim bozulmaları da bu yöntemle incelenebilmektedir (Tornari, 2007: 766). Hem atımlı lazerle hem de sürekli dalga lazeri ile üretilebilen holografik interferogramı Al Razutis ve Sally Weber'in sanatsal çalışmalarında da görmek mümkündür. Razutis, Interferometrik Hologramlar-Holocontour ve Stress Topography isimli serilerinde çizgisel soyut formları kullanmıştır (Razutis, alchemists.com). Weber ise atımlı lazer 
kullanarak yaptığı insan bedenlerini gösteren interferogramlarının birkaç tanesini birleştirerek bileşik hologram'lar oluşturmuştur (Weber, sallyweber.com).

Holografik Stereogram. Görüntülerin birbiri ardına gösterilmesiyle üç boyut etkisi ve hareket yanılsaması veren bu teknik, fotografi, sinematografi ve holografiyi birleştiren stereografik ilkelere dayanan bir tekniktir. A.B.D’li fizikçi Lloyd G. Cross, ilk önce geleneksel fotoğraf saydamları ile bir kişi ya da bir nesnenin çevresinde dönerek fotoğraflar çekmiş sonra bu serinin hologramlarını yapmıştır. Daha sonra ise bu hologramları $120^{\circ}$ ya da $360^{\circ}$ lik bir silindire monte etmiş böylece ilk holografik stereogramların ortaya çıkarmıştır (Cross, 1992: 422). Bu tekniğini, sinema kayıt tekniği ile birleştirerek geliştiren Cross, Multiplex isimli tümleştirilmiş stereogram üreten bir şirket kurmuş ve bu ismi markalaştırmıştır. Stephen Benton'1n geliştirmiş olduğu hologram çeşitleri gibi Cross'un
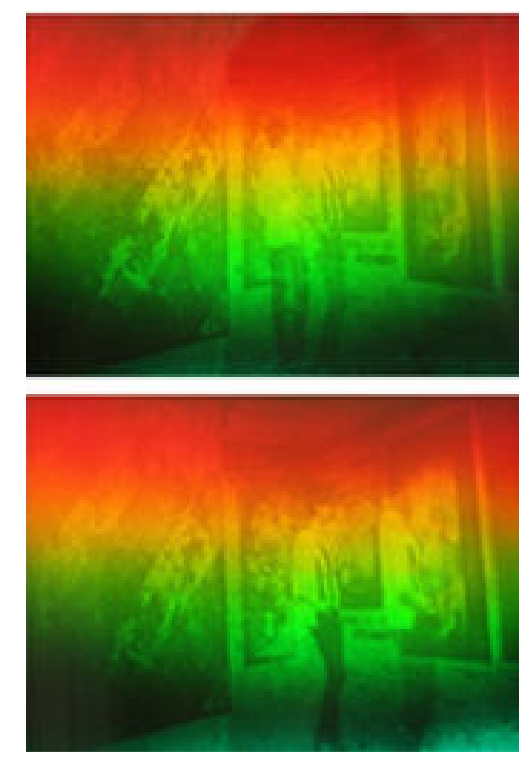

Görsel 8. Holografik Stereogram (a, b) Vildan Işık, HoloSuret: Sanal Sergi, 2012, holografik stereogram$\mathrm{H} 2$, gümüş halide film, yaklaşı $25 \mathrm{x}$ $30 \mathrm{~cm}$, aynı hologramın iki farklı açıdan görünümü. Üretim yeri: Hangyo Int. Corp. R\&D Center Holography Lab., Seul-G.Kore. geliştirdiği holografik stereogramları da holografinin sanatsal açıdan kullanımını önemli ölçüde etkilemiştir. Holografik stereogramlar genellikle bir eksen üzerinde döner fakat kısmi silindirik hologramlarda hareket ve derinlik, hologramın önündeki izleyicinin hareketi ile ortaya çıkmaktadır (MIT Leonardo, 2001: 376). Kamera ve bilgisayarlar aracılığı ile birçok farklı açıdan görüntülerin alınması ve birleştirilmesinden oluşan bu tekniğin farklı çeşitleri bulunmaktadır. En yaygın olanı, bir silindir üzerine yapılan $360^{\circ}$ stereogramlardır. Bunlar çoğullamalı ya da tümleştirilmiş hologram çeşidi olabilir. Vildan Işık’ın HoloSuret: Sanal Sergi (görsel 8) isimli çalışmasında, kameraya kaydedilen yürüme hareketi, Işık'1n tuval resimleri ile bilgisayarda hazırlanmış sanal bir mekâna aktarılmıştır. $\mathrm{Bu}$ yolla elde edilen videodan ise önce $5 \times 36$ $\mathrm{cm}$ ebatlarında lazerle görülebilen holografik stereogram kaydı (H1) sonra bu H1'den yaklaşık 25 x 30 cm'lik geçirgen beyaz 1şık hologramı (H2) yapılmıştır.

\section{HOLOGRAFÍK SANAT TERİMLERİ}

Holografi, diğer sanat dallarının kullandıkları terimlerden yeni terimler üretmiş ve kendi sanat terimlerini oluşturmaya başlamıştır. Holografik portre, gölgekayıt, bileşik 
hologram, holomontaj, gölgekayıt, çevresel holografi, holoresim, resimsel holografi, holokinetizm, holomobil, holoheykel ve holografik yerleştirme bu terimlerden bazılarıdır.

Gölgekayıt. Pozlama boyunca bir nesne, ağır ağır hareket ettirilirse sonuç görüntü üç boyutlu siyah bir boşluğa benzemektedir. Bir gölgekayıt eğer tek aşamalı olarak üretilmişse malzemenin önündeki bir yansıma olarak her zaman gerçek fakat iki aşamalı ise hem gerçek hem de sanaldır. Bu üretim, Fox Talbot tarafından kullanılan fotojenik çizim'i Moholy Nagy'nin photogram'1 ve Chiristian Shad tarafından yeniden keşfedilen shadowgram (gölgekayıt) tekniği ile doğrudan bağlantılıdır (MIT Leonardo, 2001: 379). Margaret Benyon'un 1970'de yaptığı Hot Air (Sıcak Hava) isimli çalışması ilk gölgekayıttır. Benyon bu çalışmasını non-hologram (hologram olmayan) olarak tanımlamış Rick Silberman ise yeniden isimlendirerek shadowgram (gölgekayıt) demiş ve sanatçılar tarafindan bu isim yaygın olarak kullanılmaya başlamıştır (Coyle, 1995: 23-26). Silberman'ın 1979-80 tarihlerinde Holografi Müzesi'nde sergilenen The Meeting (Toplant1), Ball and Jacks (Balo ve Valeler), Cat's Cradle (Kedi Beşiği) ve Rough Cut (Kaba Kesim) isimli çalışmaları gölgekayıt örnekleridir (De Freitas, 2008).

Bileşik Hologram. Kompozit hologram da diyebileceğimiz bu hologramlarda birden fazla hologram muhtelif şekillerde sıralanmakta veya başka bir nesneye ilave edilmektedir. $\mathrm{Bu}$ aslında kolaj mantığına dayanan bir yöntemdir. Bileşik hologramlar, duvara asılabilen geniş biçimli düzenlemelerin oluşturulmasında kullanılmaktadır. Duvara asılabilen olması yüzünden holomontage'a benzetilen bileşik hologramların üç boyutlu olanları ise holoheykel olarak tanımlanabilmektedir (Leonardo, 2001; 371). Harriet Casdin-Silver'ın yüzey üzerinde birleştirdiği üç hologramdan oluşan $70+1+2$ isimli çalışması, Rudie Berkhout'un Ward Bos'un tuval resmi ile kendi yansıma hologramlarını birleştirdiği çalışması ve Sally Weber'in holografik interforogramlarından oluşan çalışmaları bileşik hologram örnekleridir (Nigrosh, 1998 ; rudieberkhoutcollection.com ; sallyweber.com).

Çevresel Holografi. Bu terim, mimari ya da doğa ile bütünleşen holografik çalışmaları tanımlamakta kullanılmaktadır. Işıklandırmanın sınırlandırılmış olmasına rağmen çevresel holografi iç ve dış mekânlarda sık sık kullanılmaya başlamıştır. Görsel görünüşü ve uzamsal duruşundan ötürü çevresel holografi, holografik yerleştirme olarak da düşünülebilir (Leonardo, 2001; 372). Melissa Crenshaw'1n 1992'deki Water Falls II (Su Düşmesi) ve Setsuko Ishii'nin 2000'deki bir su havuzuna yerleştirilen silindir formlu hologramlardan oluşan Apollonian Gift Series (Apollon Hediye Serisi) isimli çalışmaları çevresel hologram örnekleridir (Garcia-Robles ve Oliveira, 2012). 
Holoresim. Dominique Mulhem tarafından tasarlanan holografi ve resim sözcüklerinin birleşiminden oluşan holoresim; resim, desen, kolaj vb. gibi çalışmalarda holografik baskı, folyo, film gibi çeşitli holografik görüntülerin resim gibi kullanılmasını ifade etmektedir (Leonardo, 2001; 375).

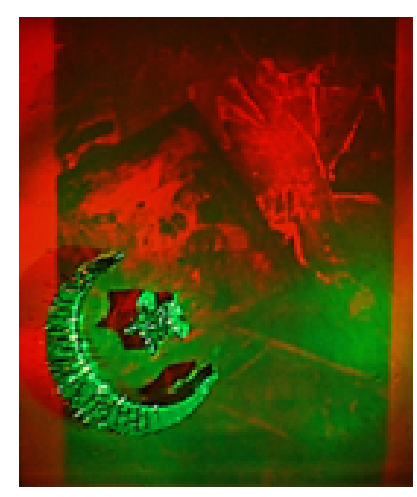

Görsel 9. Holomontaj

Vildan Işık, HoloSuret-III, 2012, çok pozlu hologram, 20 x $25 \mathrm{~cm}$. Üretim yeri: Hangyo Int. Corp. R\&D Center Holography Lab., SeulG.Kore.

Holomontaj. Fotoğrafçılıktaki fotomontaj kelimesinden esinle türetilen holomontaj ile filmleri üst üste koyma ya da görüntü bölümlerini çeşitli şekillerde birleştirme yoluyla sonuç görüntü oluşturulmaktadır. Sanatçıların, holografik üretim sürecinde yaptıkları çeşitli müdahaleleri içeren çalışmalarını ifade eden bu terim, özellikle kayıt ve banyo sürecindeki manipülasyonlarla sonuç görüntüyü sanatsal olarak değiştirme amacını taşıyan çalışmaları tanımlamak için kullanılmaktadır. Birden fazla holografik plaka katmanlar halinde bir arada kullanılabileceği gibi bir ya da birden fazla kalıp kullanarak çoklu pozlama da yapılabilmektedir. Bu teknik, sanatçılara renk ve biçimde manipülasyon yapmalarında büyük bir esneklik sağlamaktadır (Leonardo, 2001; 374). Vildan Işık'ın Holo-Suret-III (görsel 9) isimli çalışması holomontaj örneğidir. Bu çalışma, geçmişte ve günümüzde kullanılan pek çok tekniği içinde barındırmaktadır (Işsk, 2014).

Holografik Portre. Sürekli dalga lazeri kullanarak holografik stereogram, geçirgen beyaz 1şık, yansıma hologram gibi tekniklerle portre üretmek mümkündür. Ancak canlı bir modelden portre yapılmak istenirse atımlı lazerin kullanılması gerekmektedir. Çünkü canlı ve hareketli nesnelerin kaydı yalnızca atımlı lazer ile alınabilmektedir. Bu lazer çeşidinin geliştirilmesi canlı modelden holografik portre kaydı artırmıştır. Ana Maria Nicholson'ın Keith Haring 'in Portresi ve Patrick Boyd'un Lucy in a Tin Hat'1 atımlı lazer ile yapılmış yansıma holografik portrelerdir (anamarianicholson.com ; Taylor, 2012: 3). Harriet CasdinSilver ise 1990'ların sonlarında ürettiği yaklaşık bir metrelik büyük boy holografik portrelerinde, geçirgen beyaz 1şık hologram ve holografik stereogram tekniğini kullanmıştır (jonathanrossholography, 2009).

Holokinetizm. Kaynağını kinetik sanattan alan ve Venezüellalı sanatçı Ruben Nuñez tarafından 1974'te holografik sanata katılan holokinetik terimi; hologramlardaki ışı̆̆ın, renk, hareket ve titreşimlerinin üç boyutlu uzamda bulunuşunu ifade etmektedir (Pepper, 2012). HolopoemNuñez, K-soul ile birlikte 2002'de Holokinetism - Ruben Nuñez isimli bir DVD 


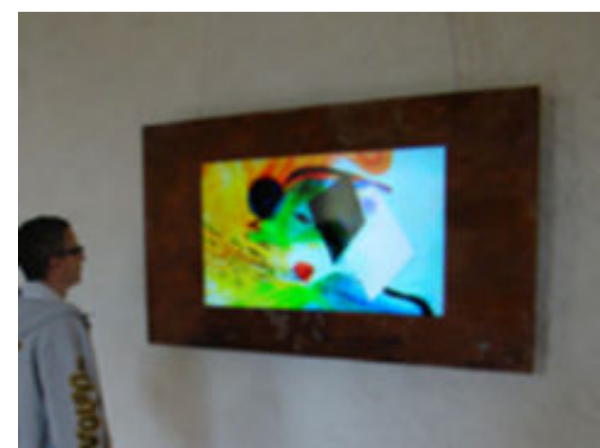

Görsel 10. Holokinetik Resim

K-soul, Cosmic Garden (Kozmik Bahçe): Thought of Light (Iş1k Düşüncesi) Serisi'nden, 2013 (jardincosmique.com).

film hazırlamışlardır. K-soul, daha sonra Nuñez'in bu terimine; Cosmic Garden (Kozmik Bahçe) olarak adlandırdığı çalışmaları için holokinetik resim ve holokinetik heykel diye iki terim daha eklemiştir. Sanatç1, Thought of Light (Iş1k Düşüncesi) isimli holokinetik resim serisinde hareket için boya yerine 1şı̆̆ı, dinamik tuval olarak da elektronik ekranı kullanmıştır. Pearl of the Universe (Evrenin İncisi) isimli holokinetik heykel serisinde ise 1 şık, renk, hareket ve titreşimi düzlem dışında oluşturmaktadır (K-soul, 2014, jardincosmique.com).

Holoheykel. Georges Dyens ve Jean Gilles tarafından önerilen holoheykel terimi, hologram ve heykelin bütünleştirildiği ya da bir heykel formu olarak hologramların ve hologramatik ışık alanlarının kullanıldığı sanat çalışmalarını ifade etmektedir (Leonardo, 2001; 375). Razutis'in Surrogate - Dressed for Art New Vouge (Vekil - Yeni Moda Sanat İçin Giydirilmiş) isimli çalışması bir holoheykel örneğidir (alchemists.com). Georges Dyens, 1994'teki Vertigo Terrare isimli yerleştirmesinde ise holoheykel, hologram, arazi sanatı, holofotogram, alüminyum, 1ş1k, plaster, kaya, müzik, hurda, kum, ahşap, polyester reçine, lazer, sis, toprak ve pleksiglas kullanmıştır (georgesdyens.com).

HoloMobil. Dieter Jung'ın eklediği bu terim, dengedeki hareket düzenini ifade etmektedir. Jung, ilk mobil heykel çalışmasını 1999'da yaptığını daha sonra bunlara hologram ekleyerek geliştirdiğini söylemektedir. Sanatçı, Navigator-Eyes of Ikarus (Yön Bulucuİkarus'un Gözü), TransOptics, HoloMobil Sürekliliği ve ShenZhen HoloMobil vb. gibi çalışmalarını holomobil olarak adlandırmaktadır (Jung, 2012: 9).

Holografik Yerleştirme. Yerleştirildiği alanla bütünleşen bu tür çalışmalar kimi zaman izleyicinin aralarında dolaşabildiği türden de olabilmektedir. Özellikle geçirgen beyaz 1şık holografisi bu tür yerleştirmeler yapmaya uygundur. Aydınlatma araçları, sergi salonunda hologramları duvardan uzağa yerleştirmesini mümkün kılmaktadır. Ikuo Nakamura’nın Houdini Art And Magic (Houdini: Sanat ve Sihir), Ray Park'1n Coexistence (Varolmayan), Setsuko Ishii'nin Frozen Time (Dondurulmuş Zaman) ve Visible Temperature (Görülebilir Sıcaklık) isimli çalışmaları holografik yerleştirme örnekleridir (MLive.com, 2013 ; facebook.com/rayhologram, 2011 ; Ishii, 2012: 4). 
Resimsel Holografi. Holografik film üzerindeki emülsiyonu kazımak, boyamak ya da kaydedilen görüntüyü muntazam olmayacak şekilde banyo etmek vb. gibi çeşitli müdahalelerle hologramın görüntüsünü değiştirilmesi yolu ile ortaya çıkan hologramı tanımlamak için kullanılmaktadır. Resimsel terimi, 20.yy’da başlayan resimsel fotoğrafi'yi kaynak almaktadır. Genel olarak bu teknikle çalışan sanatçılar, holografinin yalnızca soyut bir çehre içinde sunduğu gerçekçi ve üç boyutlu görüntüyü altüst etmeye, harap etmeye çabalamaktadır. Bunlar; ifadesel ve resimsel 1 şı eserleridir, bazen 1 ş1k resim olarak da adlandırılmaktadır (Leonardo, 2001; 377). Harriet Casdin Silver'ın Coda isimli 1990'lardaki yansıma hologramı resimsel hologram örneğidir (gallerynaga.com).

\section{Sonuç}

1960’l1 yılların sonlarından günümüze farklı hologram çeşitlerinin sanatta kullanımı, görsel ifade ve biçimlendirmeye zenginlik katmış kategorize edilmiş pek çok sanat dalının sınırlarını genişletmiştir. Farklı çeşitlerin kullanılması, holografinin kendine özgü kavram ve terimlerinin ortaya çıkması ve gelişmesine katkı sağlamasının yanı sıra 1980'lerin sonlarına doğru ayrı bir sanat dalı olarak kabul görmesi hususunda da oldukça etkili olmuştur. Holografik sanatın sadece bu çalışmada anlatılan hologram çeşitleri ile sınırlı olmadığını özellikle vurgulamak gerekmektedir. Çünkü sanatsal amaçla kullanılan ancak bu çalışmada yer almayan bilgisayarla oluşturulmuş, kabartma ve sayısal hologram vb. gibi pek çok başka hologram çeşidi de bulunmaktadır.

Holografik sanat; zaman, mekân, boyut, renk, hareket, ses, sanallık ve gerçeklik algısını eşzamanlı olarak izleyiciye sunabilmektedir. Bu özellikleri sayesinde ileride de önemli bir sanatsal ifade aracı olmaya devam edecektir.

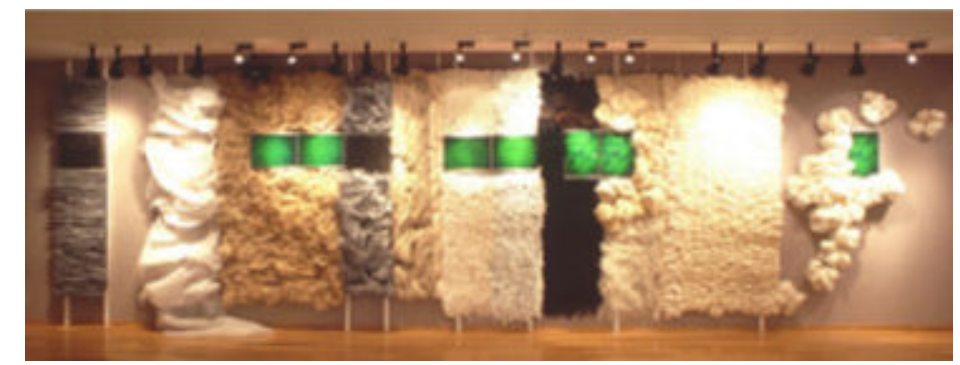

Görsel 11. Bileşik Hologram / Holografik Yerleştirme Setsuo Ishii, Visible Temperature (Görülebilir Sicaklık), 1987-88, $220 \times$ $750 \mathrm{~cm}$ (Ishii, 2012: 4). 


\section{KAYNAKÇA}

Cernecky, Jozef, Elena Pivarciova. (2011). "Possibilities and Prospect of Holography: Sandwich Method", holografia.wz.cz, http://www.holografia.wz.cz/holography/Sandwich_Method.php

Cross, Lloyd G., Cecil Cross. (1992). "HoloStories: Reminiscences and a Prognostication on Holography”, Leonardo, MIT Press.

Benyon, Margaret. "The Benyon Archive”, mbenyon.com, http://www.mbenyon.com

Coyle, Rebecca, Phillip Hayward. (1995). "Margaret Benyon: The Founding of Holographic Art”, Holographic Art in Australia, Chapter 2, University of Sydney, Power Publications, Australia.

Dan Schweitzer, (2000). “Time vs. Space: Making Time”, WaveFront Magazine, Bio-Graphic Papers, 2000, http://www.alchemists.com/visual_alchemy/wave2000-4.html, Metnin orjinali, İngiltere'deki Art in Holography-2'de ve Almanya'daki Holographic Network Konferansı'nda Ekim 1996'da sunulmuştur. Yazarın izni ile 2000'de WaveFront Magazin'de yeniden yayımlanmıştır.

De Freitas, Frank. (2008, August 04). "Rick Silberman Exhibit 1979”, http://holographica.blogspot.com/2008/08/rick-silberman-exhibit-1979.html

Garcia-Robles, R., R. M. Oliveira. (2012). “The Artistic Use of Parallax and Lenses Revealing the Invisible in Holography", 9th International Symposium on Display Holography, Journal of Physics: Conference Series 415 2013, IOP Publishing, http://iopscience.iop.org/

Georges Dyens, http://georgesdyens.com/en/om_oeuvre.php?serie=84

Işık, Vildan. (2012). Sanatsal İfade Aracı Olarak Holografi, Gazi Üniversitesi Güzel Sanatlar Enstitüsü, Sanatta Yeterlik Tezi, Ankara, Türkiye.

Işık, Vildan. (2014). "Classification of Holograms and Types of Hologram Used in Art", International Conference on Communication, Media, Technology and Design ICCMTD, 24-26 April, Istanbul, Turkey. (accepted)

Ishii, Setsuko. Setsuko Ishii's Portfolio Page, http://www.absolutearts.com/

Ishii, Setsuko. (2012). “Artistic Representation with Pulsed Holography”, 9th International Symposiumon Display Holography, Journal of Physics: Conference Series 415 (2013), IOP Publishing, p. 1-6.

Jonathan Ross Holography Collection, http://www.jrholocollection.com/

Johnston, Sean F. (2005). "Attributing Scientific and Technological Proggress: The Case of Holography", History and Technology, Universiy of Glasgow, December, S. 21, s.367-392.

Jung, Dieter. (2012). "Moments of Seeing”, 9th International Symposium on Display

Holography, Journal of Physics: Conference Series 415 2013, http://iopscience.iop.org/1742-6596/415/1/012081/pdf/17426596_415_1_012081.pdf

K-soul, (2014). "Holokinetism - Reflection on the Digital Art", Cosmic Garden Laboratory, http://www.jardincosmique.com/Publications-001-S.htm 
Nicholson, Ana Maria. (2012). “A Holographic Collaboration”, 9th International Symposium on Display Holography, Journal of Physics: Conference Series 415 2013, IOP Publishing, http://iopscience.iop.org/

Nicholson, Ana Maria. (2009). "Holography: A Love Story", anamarianicholson.com, http://66.39.59.128/AnaMariaNicholsonPaper.pdf

Nigrosh, Leon. (1998), "Body Art - Harriet Casdin-Silver Strips Us Down”, The Worcester Phoenix, November 27 - December 4, 1998, http://www.worcesterphoenix.com/archive/art/98/11/27/HARRIET_CASDIN_SILV ER.html

Pepper, Andrew. (2012). "Ruben Nuñez (1930-2012)”, Holographer.org, http://holographer.org/ruben-nunez-1930\%E2\%80\%932012/

Razutis, Al. alchemists.com, http://www.alchemists.com/visual_alchemy/west-coast2.html

Sagnotti, Leonardo. (2007). http://www.flickr.com/photos/leosagnotti/1777731865/in/photostream/

Saxby, Graham.(1994). Practical Holography, IOP Publishing Ltd., UK.

Taylor, R. (2012). "A Curious Conundrum; The State of Holographic Portraiture in the 21st Century", 9th International Symposium on Display Holography, Journal of Physics: Conference Series 415 2013, IOP Publishing, http://iopscience.iop.org/

Tornari, Vivi. (2007). "Laser Interference-based Tecniques and Applications in Stuructual Inspection of Works of Art", Anal Bioanal Chem, S. 387, 04 January, p.761-780.

Weber, Sally. "Pulsed Light", sallyweber.com, http://www.sallyweber.com/pulsed.html

\section{Anonimler}

Art in Holography. (1996). http://www.art-in-holography.org/

Artlinkart. (2008). "Unvisible - Dieter Jung Solo Exhibition", http://www.artlinkart.com/en/artist/exh_yr/6baauulm/854atvtj

Rudie Berkhout Collection. http://www.facebook.com/therudieberkhoutcollection?fref=ts

Holocenter. "Different Types and Techniques of Holography Used by Artists", http://holocenter.org/what-is-holography

Holograms.co.uk. "The History of Spatial Imaging Portraits", http://www.holograms.co.uk/portraits/page3.html

komar.cs.stthomas.edu. Komar's Korner University, "Volumetric and Holographic Imaging", http://komar.cs.stthomas.edu/qm425/02s/Lloyd3.htm

MIT Leonardo. (2001). "New Media Dictionary: Terms-Part 4: Holography”, Leonardo, Editör: Louise Poissant, Journal of the International Society for the Arts, Science and Technology, Massachusetts Institute of Technology-MIT Press, Vol. 34, No.4, p.370-380.

MIT Museum. "Holography: The Light Fantastic", http://web.mit.edu/museum/exhibitions/holography-the-light-fantastic.html

MIT News. (2003). "Holography Pioneer Stephen Benton Dies at 61", Massachusetts Institute of Technology, 12 Kasim 2003, http://web.mit.edu/newsoffice/2003/benton.html 
New York Stereoscopic Society. (2011, September). "Fine Art Holography at Hudson Beach Glass", http://www.ny3d.org/2011/10/

obel.ee.uwa.edu.au. The Optical+Biomedical Engineering Laboratory, http://obel.ee.uwa.edu.au/research/holography/intro/ 
